\title{
Supramolecular Structure of Hydrocarbon Gels of the Solvates of Lithium Tetraalkyl Borates
}

\author{
Zinaida T. Dmitrieva \\ Institute of Petroleum Chemistry, Siberian Branch of the Russian Academy of Sciences, \\ Tomsk, Russia
}

Correspondence should be addressed to: Zinaida T. Dmitrieva; ztd@ipc.tsc.ru

Received date: 25 March 2014; Accepted date: 29 May 2014; Published date: 15 September 2016

Academic Editor: Waldemar Maniukiewicz

Copyright (C) 2016. Zinaida T. Dmitrieva. Distributed under Creative Commons CC-BY 4.0

\begin{abstract}
Mechanical, thermal and sedimentation stability of supramolecular structure of hydrocarbon gels of $[\mathrm{B}(\mathrm{OR}) 4] \mathrm{L} \cdot \mathrm{nXR}$ solvates $(\mathrm{X}=\mathrm{HNR}, \mathrm{OR}$ and $\mathrm{HO})$ is investigated as a function of chemical nature of a solvating agent, the complex-to-solvating agent molar ratio, filler concentration and temperature under the conditions of deformation shift. The mechanism of formation of supramolecular structure of the gel matrix in hydrocarbon solutions of lithium tetraalkylborates and their solvates is discussed.
\end{abstract}

Keywords: Structure, hydrocarbon gels, lithium tetraalkylborates.

\section{Introduction}

The structuring of hydrocarbon fluids is of great importance in the technology of hydraulic fracturing of low permeable gasand oil-bearing reservoirs. Viscoelastic thixotropic fluids and gels are used to transport dispersed (propping) material into the forming channels in order to increase reservoir filterability $\left[\begin{array}{ll}1, & 2\end{array}\right]$. $\left[\mathrm{B}(\mathrm{OR})_{4}\right] \mathrm{Li}$ complexes are known to polyassociate in hydrocarbon solutions to form viscoelastic fluids and gels [3]. Viscoelasticity, which characterizes the stability of supramolecular structure of the solutions and gels of the complexes to thermomechanical deformation, depends on the length and number of alkyl fragments (R). In the polyassociates of lithium tetraalkylborates, a lithium ion has two vacant coordination bonds. Using the electronic deficiency of lithium, it is possible to increase the number of alkyl groups via solvation of the complex (C) with electron-donor compounds in order to improve the following rheological properties of fluids: thixotropy, viscoelasticity, mechanical and thermal stabilities of the gels.

Cite this Article as: Zinaida T. Dmitrieva (2016)," Supramolecular Structure of Hydrocarbon Gels of the Solvates of Lithium Tetraalkyl Borates ", Journal of Research \& Developments in Chemistry, Vol. 2016 (2016), Article ID 313916, DOI: 10.5171/2016.313916 


\section{Results}

In this paper, we investigated the structuring ability of the solvates of the complexes in the solution of diesel fuel (DF), the stability of supramolecular structure of the gels by the methods of rheometry and filler (proppant) sedimentation. We also defined the rheological constants and the viscous flow activation energy for the gels under conditions of ultimate shear deformation for the molecular ratio $\mathrm{C}$ : SA ranging from 1 $: 0$ to $1: 2.5$ in the temperature range from 20 to $140^{\circ} \mathrm{C}$. Mixtures of [t$\left.\mathrm{C}_{4} \mathrm{H}_{9} \mathrm{OB}(\mathrm{OR})_{3}\right] \mathrm{Li}$ complexes of even series, where $\mathrm{R}=\mathrm{C}_{6}-0.4 ; \mathrm{C}_{8}-46.3 ; \mathrm{C}_{10}-52.3$ and $\mathrm{C}_{12}-1.0$ wt. \%, were chosen as structureforming agents. Alcohols, ethers and amines: $\quad n-\mathrm{C}_{8} \mathrm{H}_{17} \mathrm{OH}, \quad n-\mathrm{C}_{10} \mathrm{H}_{21} \mathrm{OH}$, (n-
$\left.\mathrm{C}_{8} \mathrm{H}_{17}\right)_{2} \mathrm{O}$, (n- $\left.\mathrm{C}_{10} \mathrm{H}_{21}\right)_{2} \mathrm{O}$, (n- $\left.\mathrm{C}_{8} \mathrm{H}_{17}\right)_{2} \mathrm{NH}$ and $\left(\mathrm{n}-\mathrm{C}_{10} \mathrm{H}_{21}\right)_{2} \mathrm{NH}$ were investigated as solvating compounds. Solvating agents (SA) were chosen taking into account their electron-donor properties and structural compliance with alkyl groups of the initial $\left[\mathrm{t}-\mathrm{C}_{4} \mathrm{H}_{9} \mathrm{OB}(\mathrm{OR})_{3}\right] \mathrm{Li}$ complexes $\left(\mathrm{R}=\mathrm{n}-\mathrm{C}_{8} \mathrm{H}_{17}\right.$, $n-\mathrm{C}_{10} \mathrm{H}_{21}$ ). It was found out that gel viscosities of all solvates of the complexes rapidly increased with the molar content of the solvating agent, reaching a maximum value (198 ... 325 Pa•s) for C: SA ranging from $1: 1$ to $1: 2.0$ (Fig. 1). The viscosity of the initial complexes under the same conditions was 7 ... 48 Pa•s. For the molecular ratio C: SA higher than $1: 2$, the viscosity of solvate gels decreased. An excess of SA destroyed the supramolecular structure (SMS) of the gel.

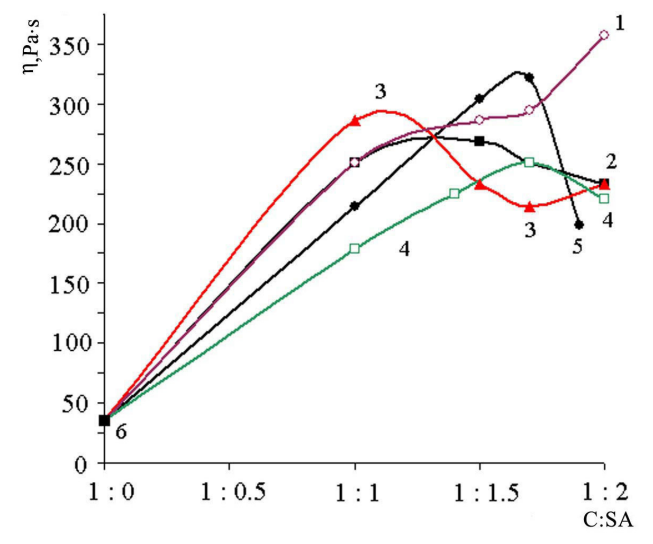

\section{Figure1: Variation in effective dynamic viscosity $(\eta)$ for the gels of the solvates of the complexes (C) as a function of $S A$ and $C$ : $S A$ (concentration $C=2.0 \mathrm{wt} . \%$ ) for the $S A$ : $\mathrm{HN}\left(\mathrm{C}_{8} \mathrm{H}_{17}\right)_{2}$ (1); ROH mixture (2); $\mathrm{O}\left(\mathrm{C}_{10} \mathrm{H}_{21}\right)_{2}(3) ; \mathrm{C}_{8} \mathrm{H}_{17} \mathrm{OH}(4) ; \mathrm{O}\left(\mathrm{C}_{8} \mathrm{H}_{17}\right)_{2}$ (5) and $\left[\mathrm{t}-\mathrm{C}_{4} \mathrm{H}_{9} \mathrm{OB}(\mathrm{OR})_{3}\right] \mathrm{Li} \mathrm{(6)}$}

The solvates of the complexes with dialkyl ethers and fatty alcohols maximize viscoelasticity of the gels in a diesel fuel in the range of the $\mathrm{C}$ : SA molecular ratios from 1.2 to 1.7 (Fig. 1, curves 2-5), while those with dialkylamines gradually increase it in the whole range of the molecular ratios of $\mathrm{C}: \mathrm{SA}=1: 1 \ldots 1: 2$ (Fig. 1, curve 1). Thus, the solvates of the complexes in the diesel fuel (DF) significantly increase gel viscoelasticity as compared to the gels of non-solvated complexes (Fig. 1, dot 6), prepared under similar conditions. Moreover, the increase in gel viscoelasticity of the solvated complexes continues in the whole range of deformation shear rates $(\gamma)$ from 0.17 to $1312 \mathrm{~s}^{-1}$ (Fig. 2). In the range of the $\mathrm{C}: \mathrm{SA}$ molecular ratios from $1: 0$ to $1: 2.5$, the index of non-Newtonian behavior of the structured DF decreases from 0.38 to 0.16 .

An increase in dynamic viscosity and shear stress $(\tau)$ in the gels of the solvated 
complexes depends on the nature of the electron-donor compound and the C: SA molecular ratio. The complexes of lithium tetra-alkyl borates solvated by the compounds, whose molecules contain two alkyl groups (dialkyl ethers and dialkylamines), increase gel viscoelasticity greater than those containing alcohol solvates. The gels of the latter, however, show maximum elastic resistance to deformations especially in comparison with the gels of ether solvates (Fig. 2). The gels of the alcohol solvates in the range of ultimate shear deformations (200 Pa) flow with increasing viscosity (Fig. 2, curve 1), while viscosity of the gels of solvates with didecyl ether is stable only up to $75 \ldots 100$ Pa (Fig. 2, curve 3).

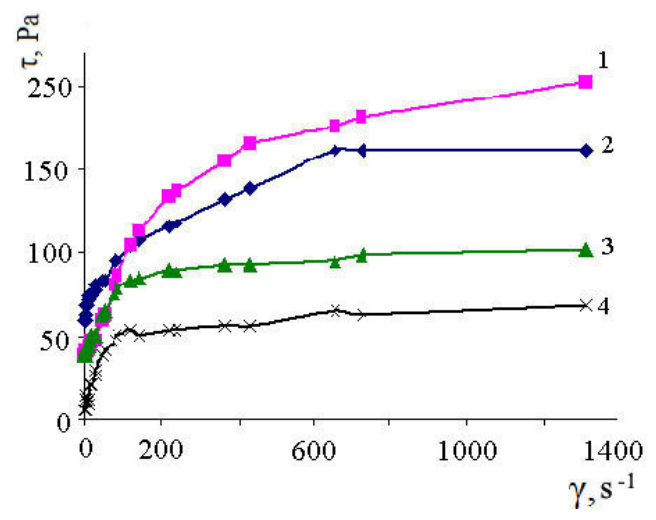

Figure 2: Curves of viscoelastic flow for the gels of the complexes and their solvates for $\mathrm{C}$ : $\mathrm{SA}=1$ : 2; SA: ROH mixture (1); $\mathrm{HN}\left(\mathrm{C}_{8} \mathrm{H}_{17}\right)_{2}(2) ; \mathrm{O}\left(\mathrm{C}_{10} \mathrm{H}_{21}\right)_{2}(3)$ and $\left[t-\mathrm{C}_{4} \mathrm{H}_{9} \mathrm{OB}(\mathrm{OR})_{3}\right] \mathrm{Li}$

While the effective viscosity of $[t$ $\left.\mathrm{C}_{4} \mathrm{H}_{9} \mathrm{OB}(\mathrm{OR})_{3}\right] \mathrm{Li} 2 \mathrm{HNR}_{2}$ gels is higher than that (Fig. 1, curve 1) of the gels of the alcohol solvates (curve 2), under mechanical deformation and heating it decreases to the values typical of the gels of alcohol and ether solvates (Fig. 3, curves 24). Up to $80^{\circ} \mathrm{C}$, the gels of the alcohol solvates of the complexes flow at high and constant viscosity but with lower activation energy (Fig. 4, curve 3), as compared to the gels of amine and ether solvates (curves 2 and 4).

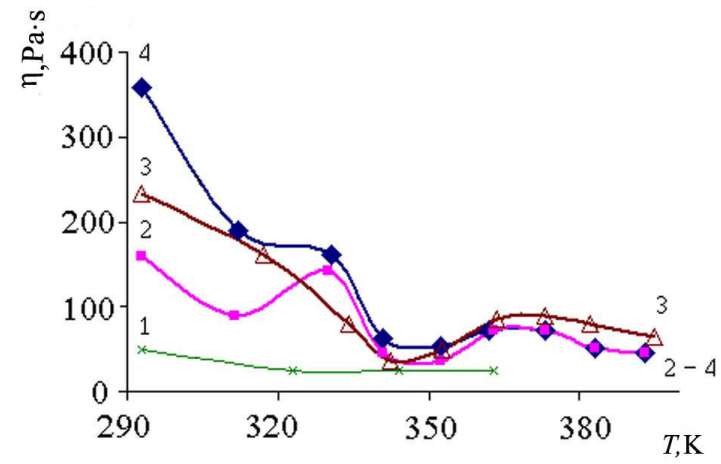

Figure 3: Variation in viscosity of the gels of the solvates of the complexes for $\mathrm{C}: \mathrm{SA}=$ $1: 2, C=2.0$ wt. $\%$ as a function of temperature: $\left[t-\mathrm{C}_{4} \mathrm{H}_{9} \mathrm{OB}(\mathrm{OR})_{3}\right] \mathrm{Li}(1) ; \mathrm{SA}: \mathrm{O}\left(\mathrm{C}_{8} \mathrm{H}_{17}\right)_{2}(2)$; ROH mixture (3) and $\mathrm{HN}\left(\mathrm{C}_{8} \mathrm{H}_{17}\right)_{2}(4)$ 


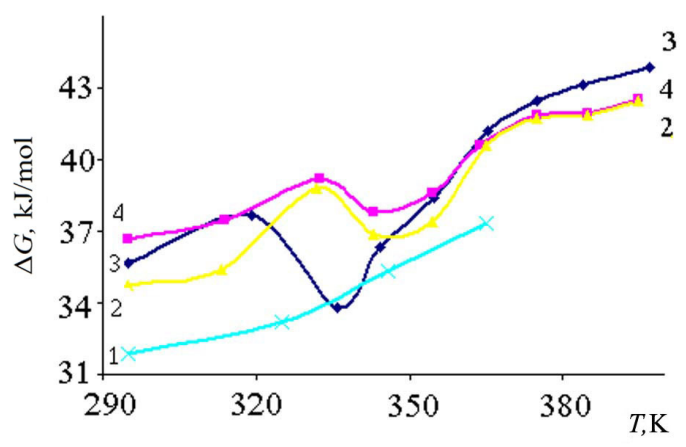

Figure 4: Variation in the activation energy of viscoelastic flow of the gels $(\Delta G)$ of the solvates of the complexes for $\mathrm{C}: \mathrm{SA}=1: 2, \mathrm{C}=\mathbf{2 . 0} \mathrm{wt}$. \% as a function of temperature: [tC4H9OB(OR)3]Li (1); SA: O(C8H17)2 (2); ROH mixture (3) and HN(C8H17)2 (4)

To study the sedimentation stability of the filler in the DF gels, use was made of proppant particles with a diameter of 0.8 $\mathrm{mm}$ and a weight of $0.003 \mathrm{~g}$. Sedimentation of a single particle from the surface layer of the gel and the filler in the bulk of the gel was measured in glass cylinders placed in an oil thermostat made of transparent glass. Shown in fig. 5 is the dependence of the results of filler sedimentation in the bulk of the gels of the complexes on the concentration of the complex and the molecular ratio $\mathrm{C}$ : SA. For a 2 wt. \% concentration of the complex solvated by the dioktylamine and the molecular ratio $\mathrm{C}$ $: \mathrm{SA}=1: 1.5$, the filler sedimentation stability in their gels reaches its maximum (Fig. 5a, curve 4). However, in this case, the time during which the filler sedimentation is maintained stable is shorter than in the gel of a non-solvated complex for $\mathrm{C}=3 \mathrm{wt}$. $\%$ (Fig. 5a, curve 5), and significantly shorter than it is under similar structuring conditions for the gels of the complex solvated by a mixture of alcohols (Fig. 5b, curve

5)
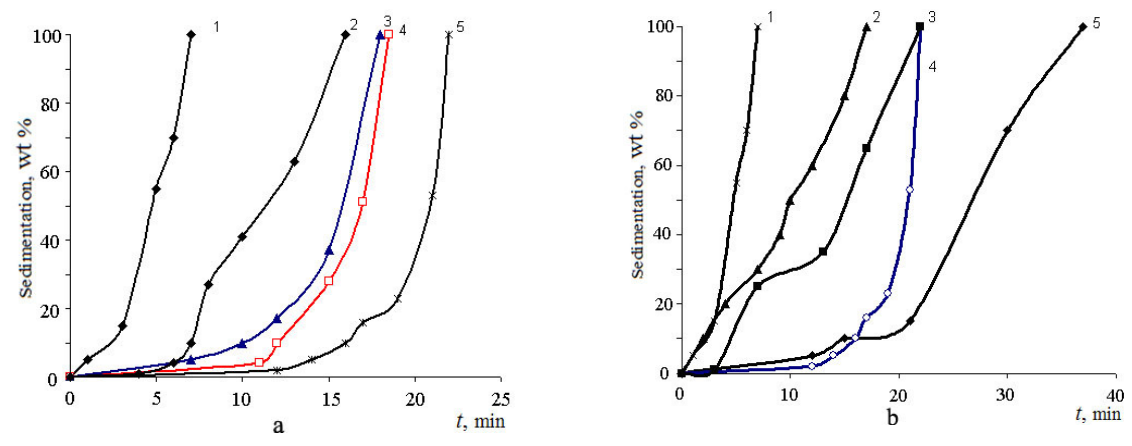

Figure 5: Sedimentation stability of the filler (20 wt. \%) at $90{ }^{\circ} \mathrm{C}$ in a diesel fuel structured by lithium tret-butyltrialkylborate $(2.0 \mathrm{wt} . \%)$ and its solvate: with dioktylamine for the $C$ : SA molecular ratios: 1 : 0 (1); 1 : 2.0 (2); 1 : 1.0 (3); 1 : 1.5 (4) for $\mathrm{C}=3 \mathrm{wt} . \%$, and $1: 0(5)$ for $\mathrm{C}=2$ wt. $\%(a)$ and with a mixture of alcohols of $\mathrm{C}_{6}-0.4, \mathrm{C}_{8}$ 46.3, $C_{10}-52.3, C_{12}-1.0$ for different molecular ratios $C: S A: 1: 0(1) ; 1: 2.0$ (2); 1 : 1.0(3); $1: 0$ (4) and $1: 1.5(5)$ for $C=3$ wt. $\%(b)$

The behavior of sedimentation stability of proppant in the gels as a function of the nature of the solvating agent and the $\mathrm{C}: \mathrm{SA}$ molecular ratio agrees well with the viscoelastic flow curves for the gels of solvates of the complexes (Fig. 2). Alcohol solvates of the complexes increase the sedimentation stability of the filler (Fig. 5b) more efficiently, because they form more elastic gels (Fig. 2, curve 1) as compared to 
dioktylamine solvates (curve 2). The duration of stable sedimentation of a $20 \mathrm{wt}$. $\%$ filler at $90{ }^{\circ} \mathrm{C}$ in the gels of alcohol solvates is twice higher (Fig. 5b) than that in the gels of dioktylamine solvates of the complexes, which confirms the thixotropy and high viscoelastic properties of the supramolecular structure of the gels of alcohol solvates of lithium tetraalkyl borate.

Table 1: Variation in the rate constant $\left(k, s^{-1}\right)$ for the sedimentation of filler (20 wt.\%) in the gels of solvates of complexes at $90^{\circ} \mathrm{C}$ and in the concentration of the complex of 2.0 wt \% depending on the nature of the SA and C : SA

\begin{tabular}{|c|c|c|c|c|}
\hline \multirow{2}{*}{ SA } & \multicolumn{4}{|c|}{ C:SA } \\
\cline { 2 - 5 } & $1: 0$ & $1: 1.0$ & $1: 1.5$ & $1: 2.0$ \\
\hline Dioktylamine & 0.50 & 0.26 & 0.39 & 0.34 \\
\hline $\begin{array}{c}\text { Mixture of alcohols } \\
\mathbf{C}_{\mathbf{4}}-\mathbf{0 . 4}, \mathbf{C}_{\mathbf{8}}-\mathbf{4 6 . 3}, \\
\mathbf{C}_{\mathbf{1 0}} \mathbf{- 5 2 . 3}, \mathbf{C}_{\mathbf{1 2}}-\mathbf{1 . 0} \text { wt. \% }\end{array}$ & 0.50 & 0.20 & 0.12 & 0.14 \\
\hline
\end{tabular}

Unlike other solvates, alcohol solvates of the complexes in hydrocarbon liquids form more elastic gels in terms of their rheological properties, which ensure their stability under the conditions of thermomechanical deformation. It is much easier for the supramolecular structure of alcohol solvates of complexes during deformation of their gels to generate and store elastic energy due to the formation of more labile intramolecular hydrogen bonds and the high rate of the gel structure relaxation. This is also supported by the values of the constants of the rate of filler sedimentation in the gels of solvates of the complexes (Table 1) and agrees well with the results of sedimentation stability for the filled compositions (Fig. 5).

Table 2: Sedimentation of proppant in the DF gel based on the complex solvated by a mixture of alcohols at a ratio of $C: S A=1: 2$ and the concentration of $C=2.0 \mathrm{wt}$. $\%$, and Mixture of alcohols $=\mathbf{1 . 8 5} \mathrm{wt}$. $\%$ as a function of the filler temperature and concentration

\begin{tabular}{|c|c|c|}
\hline $\begin{array}{c}\text { Temperature of } \\
\text { the filled } \\
\text { composition, } \\
\text { oC }\end{array}$ & $\begin{array}{c}\text { 50\% / 30 \% of filler } \\
\text { amount of proppant } \\
\text { after sedimentation, } \\
\text { wt. \% }\end{array}$ & $\begin{array}{l}\text { Time of } \\
\text { sedimentation, } \\
\text { min }\end{array}$ \\
\hline $\mathbf{7 0}$ & $0.0 / 1.0$ & $25 / 9$ \\
\hline $\mathbf{8 0}$ & $6.7 / 10.0$ & $10 / 10$ \\
\hline $\mathbf{8 5}$ & $11.6 / 12.4$ & $15 / 10$ \\
\hline $\mathbf{9 0}$ & $5.0 / 2.7$ & $10 / 19$ \\
\hline $\mathbf{9 5}$ & $10.0 / 1.0$ & $10 / 6$ \\
\hline $\mathbf{1 0 5}$ & $16.7 / 4.0$ & $15 / 20$ \\
\hline
\end{tabular}

The sedimentation stability of the filled composition increases within the whole temperature range with the filler content in the gels of solvates of the complexes from 30 to $50 \mathrm{wt}$. \% (Table 2). According to visual observations, the gel adhesion to glass decreases more significantly for a composition filled with $50 \%$ of proppant as compared to that with $30 \%$ of proppant. Under the influence of the proppant adsorption surface, the gel in the proppantfilled composition compresses due to this the sedimentation stability of the sand seems to increase. Based on the reduced gel adhesion in the proppant-filled composition, an assumption could be made 
that this would reduce the energy required to pump the composition into the channel (fracture) of a subterranean reservoir.

Indicators of sedimentation of a single proppant particle in the diesel fuel structured with a mixture of complexes and their solvates are determined depending on the gelling agent concentration within the temperature range from 70 to $142{ }^{\circ} \mathrm{C}$ (Table 3). With the increase in concentrations of the mixture of complexes and their alcohol and dioktylamine solvates, the sedimentation (settling) of a single proppant particle is inhibited and the temperature range of the particle sedimentation stability is extended.

Table 3: Variation in the sedimentation rate $(\mathrm{S}, \mathrm{cm} / \mathrm{min})$ of a single filler particle in a structured diesel fuel vs. the complex (C) concentration, mixture of alcohols (AM), and dioktylamine (DOA) in the solvates of the complexes for the $C: S A$ ratio $=1: 2$

\begin{tabular}{|c|c|c|c|c|c|c|}
\hline \multirow{3}{*}{$\begin{array}{c}\text { Gel } \\
\text { temperature, } \\
{ }^{\circ} \mathrm{C}\end{array}$} & \multicolumn{6}{|c|}{ Concentration, wt. $\%$} \\
\hline & \multicolumn{2}{|c|}{ C } & \multicolumn{2}{|c|}{ in solvate, $C+A M$} & \multicolumn{2}{|c|}{ in solvate, $C+D O A$, } \\
\hline & 1.7 & 2.0 & $1.7+0.95$ & $2.0+1.10$ & $1.7+1.57$ & $2.0+1.85$ \\
\hline $70 \ldots 75$ & 2.0 & 1.1 & 0.2 & 0 & 0.5 & 0 \\
\hline $80 \ldots 85$ & 3.0 & 1.3 & 0.3 & 0.1 & - & - \\
\hline $90 \ldots 93$ & 5.5 & 5.4 & 0.9 & $\begin{array}{c}0.4 \\
(1.4)^{* *}\end{array}$ & 4.6 & 1.5 \\
\hline $100 \ldots 103$ & $\begin{array}{c}8.8 \\
(2.7)^{*} \\
\end{array}$ & 6.3 & 2.4 & $\begin{array}{c}1.8 \\
(4.0)^{* *}\end{array}$ & 9.1 & 6.3 \\
\hline $106 \ldots 110$ & 13.6 & $\begin{array}{c}7.2 \\
(5.8)^{*}\end{array}$ & 10.7 & $\begin{array}{c}2.6 \\
(4.5)^{* *}\end{array}$ & 13.5 & 10.7 \\
\hline $119 \ldots 120$ & 22.6 & 18.0 & 17.9 & $\begin{array}{c}11.0 \\
(7.4)^{* *}\end{array}$ & 17.9 & 15.2 \\
\hline $130 \ldots 131$ & - & 34.7 & - & $\begin{array}{c}20.1 \\
(12.3)^{*}\end{array}$ & - & 29.8 \\
\hline $139 \ldots 142$ & - & - & - & $\begin{array}{c}16.2 \\
(6.2)^{*}\end{array}$ & - & - \\
\hline
\end{tabular}

The second measurement of particle sedimentation in the gel: in 1 day* and in 2 days**

The structure of gels of alcohol solvates of the complexes compared to those of dioktylamine solvates and non-solvated complexes corresponds to the maximum sedimentation resistance of a single proppant particle within the temperature range from 70 to $120{ }^{\circ} \mathrm{C}$. Contrary to dioktylamine solvates and non-solvated complexes, the alcohol solvates in a diesel fuel solution form thermally more stable gels and thus more heat-resistant filled compositions based on them. It was found out that the thermal treatment of gels of the complexes and those of solvates within 1.0 - 1.5 hours with a gradual $3-10{ }^{\circ} \mathrm{C}$ increase in the temperature up to $140{ }^{\circ} \mathrm{C}$ significantly improves sedimentation of a single sand particle even after 1-2 days of storing the heat-treated gel at room temperature (Table 3).

An intense and very fast (7-10 s) increase in viscosity accompanying the mixing of boron with lithium alkoxides in a hydrocarbon liquid along with the experimental fact that the complexes $\left[\mathrm{B}(\mathrm{OR})_{4}\right] \mathrm{Li}$ and $\left[t-\mathrm{C}_{4} \mathrm{H}_{9} \mathrm{OB}(\mathrm{OR})_{3}\right] \mathrm{Li}$ undergo maximum salvation by two electron-donor molecules only without destroying the supramolecular structure (SMS) are indicative of the association of the complexes and their solvates through the $\mathrm{Li}$ .. O bond in a macrocyclic structure (form), which could be due to the nature of lithium alkoxide (Fig. 6). 

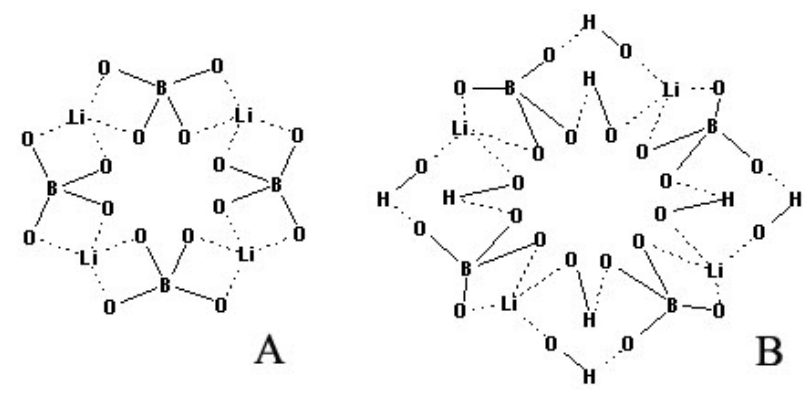

\section{Figure 6: Macrocyclic structure of the $\mathrm{Li} \cdots \mathrm{O}$ bond associated complex $(A)$ and its alcohol solvate $(B)$}

The association of complexes via $\mathrm{Li} \bullet \bullet 0$ bonds in the macrocyclic structure spontaneously specifies the pathway of association of lithium tetraalkyl borates as an interaction between alkyl fragments. The complexes are associated through alkyl groups in the thermodynamically favorable direction to form stable molecular rodshaped structures (hollow tubes). This association mechanism of the complex is confirmed by unusually strong intermolecular interaction between the alkyl groups, which in the gas phase was found to be stronger than the $\mathrm{C}$ - $\mathrm{C}$ bond according to the mass spectrometry data [4]. The phenomenon of the anomalously strong dispersion interaction between the alkyl groups $\mathrm{R} \cdots \mathrm{R}$ is possible only in closed (cyclic) systems, which ensures the stability of poly-associated complexes under mechanical and thermal impact. The poly-associated complexes formed by the represent a primary supramolecular structure.

Due to the forces of dispersion interaction between the alkyl groups, super-molecules (tubes) are self-assembled to form a secondary supramolecular structure (Fig. 7). When a gel is exposed to shear stress, it is only its secondary supramolecular structure that is decomposed, while the associates (tubes) flow without changing their structure. Hence, the gels of complexes and solvates flow at a low activation energy $\Delta \mathrm{E}$ (Fig. 4). An easy transition from a three-dimensional supramolecular structure (Fig. 7 B) into a cluster-like layered structure (A) induced by deformation and a reverse transition after the loading is removed corresponds to a high rate of relaxation of the supramolecular structure and to a constant viscosity at which the gels of solvates of the complexes flow (Fig. 2).

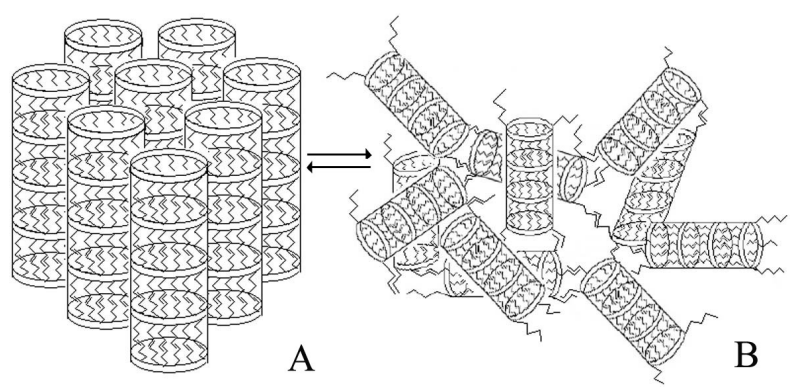

Figure 7: Mechanical model of the supramolecular structure of polyassociated lithium tetraalkylborates: two-dimensional (A) and three-dimensional (B) 


\section{Conclusion}

The electron-deficient state of the lithium atom in the $\left[\mathrm{B}(\mathrm{OR})_{4}\right] \mathrm{Li}$ and the unsaturation of its coordination sphere allowed us to develop the principle of solvation of complex lithium tetraalkylborates with electron-donor compounds (such as, dialkylamines, dialkyl ethers, aliphatic alcohols). An analysis of the results of investigation of viscoelasticity and thixotropy of gels, sedimentation stability of the filled compositions, and energy kinetics parameters as a function of temperature, chemical nature, and molar content of the solvating agent has confirmed that solvation of lithium tetraalkylborates can be used to control the processes of structure formation in hydrocarbon solutions of the complexes within a wide range of thermomechanical deformations.

\section{References}

1. Dmitrieva, Z. T., Mikov, A. I. and Shipilov, A. I. (2008) Patent 2322475 RF "Structured liquid sand-carrier," registered 04.08.2006, published 20.04.2008. Bulletin, (11) 8.
2. Dmitrieva, Z. T. (2003) "Fracturing Fluids for Low-Permeability Gas- and Oil Saturated Reservoirs," Interval, 5(52) 4850. [In Russian]

3. Dmitrieva, Z. T. and Khat'kov, N. D. (2007) "Investigation of the Supramolecular Structure Stability of the Gels of Lithium Tetraalkylborate by Acousto-Optic Method," Journal of Engineering Physics, 80 (4) 13-19. [In Russian

4. Dmitrieva Z. T. (2007) "Investigation of the Properties of Lithium Tetraalkylborate by the Method of Thermogravimetric Analysis," Journal of Applied Chemistry, 80 (1) 111-112. [In Russian]

5. Dmitrieva Z. T. (2005) "Macrocyclic Structures of Associated Complexes of Lithium

Tetraalkylborates," Russian Chemical Bulletin, International Edition, 54 (4) 1063-1064. 